\title{
Analysis of formulation effects in the dissolution of ibuprofen pellets
}

\author{
F.O. Costa ${ }^{\text {a }}$, A.A.C.C. Pais ${ }^{\text {b }}$, J.J.S. Sousa ${ }^{a, *}$ \\ ${ }^{a}$ Faculdade de Farmácia, Universidade de Coimbra, P-3004-535 Coimbra Codex, Portugal \\ b Departamento de Química, Universidade de Coimbra, P-3004-535 Coimbra Codex, Portugal
}

Received 27 February 2003; received in revised form 22 September 2003; accepted 6 October 2003

\begin{abstract}
In this work the effects of citric acid and of two common fillers, lactose (soluble) and tricalcium phosphate (insoluble) are examined on the release profiles from pellets, using ibuprofen as a model drug with $\mathrm{pH}$-dependent solubility. Also studied is the dependence of these profiles on the specific surface area, bulk density, apparent density, porosity and porosity parameters (pore size distribution, total pore surface area, mean pore diameter and pore shape), as determined by mercury intrusion porosimetry. Pellets with high porosity and total pore surface area but small median pore diameter (tricalcium phosphate pellets-IPM) are found to produce similar dissolution results to those of low porosity and low total pore surface area, but having a high median pore diameter (lactose pellets-ILM), irrespective of the solubility of excipients. Addition of citric acid causes a delay in the initial dissolution for both formulations. During dissolution, however, citric acid reduces the median pore diameter of lactose-based pellets. In contrast, in tricalcium phosphate/citric acid pellets (CIPM), this parameter increases considerably during dissolution, when compared to the IPM formulation. These findings may justify the contrasting dissolution behaviors of CIPM and CILM (lactose/citric acid) pellets, after their common behavior in the initial stages, and show that porosity and its related parameters, along with physical properties of excipients such as solubility, density and specific surface area, are helpful to predict pellet behavior in drug release profiles.
\end{abstract}

(C) 2003 Elsevier B.V. All rights reserved.

Keywords: Pellets; Drug release; Porosity; Specific area; Density; Porosity parameters

\section{Introduction}

Extrusion-spheronization technology (Conine and Hadley, 1970; Reynolds, 1970) has been adopted by the pharmaceutical industry for production of pellets, which can be either filled into capsules or compacted into tablet form . Factors that mostly influence pellet production have been studied and found to be re-

\footnotetext{
* Corresponding author. Tel.: +351-239-837-850; fax: +351-239-837-731.

E-mail address: jjsousa@ci.uc.pt (J.J.S. Sousa).
}

lated to formulation (Tomer et al., 2001; Sousa et al., 2002a,b), processing conditions (Sousa et al., 1996; Chopra et al., 2001; Alvarez et al., 2002) and equipment used (Berggren and Alderborn, 2001; Pinto et al., 2001).

Formulation parameters, irrespective of the solid dosage form, influence both the process and the quality of the final product. The presence of soluble or insoluble fillers (Khan and Zhu, 1998; Sousa et al., 2002a) and of organic acids as pH adjusters (Nykänen et al., 1999; Krogars et al., 2000) have already been identified as factors which can modulate drug release. 
In particular, the morphology of pellets and total structure can change with any variation in formulation or in materials properties, affecting quality parameters such as porosity and surface roughness (Chopra et al., 2001). These properties are considered to have a great influence on coating, flow and packing during capsule filling or tabletting (Rodriguez et al., 2001; Johansson and Alderborn, 2001). Porosity and pore structure can also provide relevant information for predicting the disintegration, dissolution, adsorption and diffusion behavior of drugs (Dees and Polderman, 1981). Recent studies (Mehta et al., 2000) have shown that porosity parameters, such as pore size distribution, total pore surface area, mean pore diameter and pore shape of pellets formulated with an insoluble drug, correlate with drug release.

The aim of our work is to study the effect of formulation variables (using soluble and insoluble fillers and citric acid) on drug release and their relation to specific surface area, bulk density, apparent density, porosity and porosity parameters. Ibuprofen was used as a model drug which has a pH-dependent solubility. Pellets were prepared by the extrusion-spheronization method.

\section{Experimental procedure}

\subsection{Materials}

In this work, ibuprofen (Shasun, batch IBU 0001097, particle size of $70.04 \pm 3.8 \mu \mathrm{m}$, shelf-life $12 / 04$ ) was used as a model drug with $\mathrm{pH}$-dependent solubility. Microcrystalline cellulose (Microcel PH 101, Sagran, Milan, Italy). Lactose monohydrate (Granular ${ }^{\circledR}$ 200, Meggle, Wasserburg, Germany) and tricalcium phosphate (Lusifar, Lisbon, Portugal) were used as soluble and insoluble fillers, respectively, and citric acid (Vaz Pereira, Portugal) as a $\mathrm{pH}$ adjuster. Sodium hydroxide and potassium dihydrogenophosphate, analytical grade (Merck), were used in $\mathrm{pH}$ $7.2 \pm 0.05$ phosphate buffer preparation.

Ibuprofen solubility at $\mathrm{pH} 7.2 \pm 0.05$ and at a temperature of $37 \pm 0.5^{\circ} \mathrm{C}$, was determined spectrophotometrically at $264 \mathrm{~nm}$ (Shimadzu UV-1603, Shimadzu Co., Kyoto, Japan). The apparent powder densities were determined using a helium pycnometer (AccuPyc 1330, Micromeritics, Norcross, USA).
Table 1

Physical characteristics of ibuprofen and excipients

\begin{tabular}{|c|c|c|c|}
\hline Raw materials & $\begin{array}{l}\text { Specific } \\
\text { surface area } \\
\left(\mathrm{m}^{2} \mathrm{~g}^{-1}\right)\end{array}$ & $\begin{array}{l}\text { Apparent } \\
\text { density at } \\
24 \pm 1^{\circ} \mathrm{C} \\
\left(\mathrm{g} \mathrm{cm}^{-3}\right)\end{array}$ & $\begin{array}{l}\text { Solubility } \\
\text { at } 25^{\circ} \mathrm{C} \\
\left(\mathrm{mg} \mathrm{ml}^{-1}\right)\end{array}$ \\
\hline Ibuprofen & & $1.118 \pm 0.001$ & $6.5^{\mathrm{a}}$ \\
\hline $\begin{array}{l}\text { Monohydrate } \\
\text { lactose }\end{array}$ & $0.24-0.25^{\mathrm{b}}$ & $1.542 \pm 0.002$ & $215.98^{\mathrm{b}}$ \\
\hline $\begin{array}{l}\text { Tricalcium } \\
\text { phosphate }\end{array}$ & $70-80^{\mathrm{b}}$ & $2.985 \pm 0.003$ & $0.01^{\mathrm{c}}$ \\
\hline Citric acid & & $1.57 \pm 0.001$ & $>1000^{\mathrm{b}}$ \\
\hline Microcel PH 101 & $1.06-1.12^{\mathrm{b}}$ & $1.580 \pm 0.001$ & $0.0^{\mathrm{c}}$ \\
\hline
\end{tabular}

${ }^{\mathrm{a}}$ HPE (2000).

${ }^{b}$ Determination at $\mathrm{pH} 7.2 \pm 0.05^{\circ} \mathrm{C}$ and $37 \pm 0.5^{\circ} \mathrm{C}$.

${ }^{c}$ Sousa et al. (2002b).

These properties are shown in Table 1, as well as solubility of excipients and their specific surface area values obtained from the literature (HPE, 2000).

\subsection{Preparation of pellets}

Pellets were prepared by the extrusion-spheronization method. Four different formulations were considered: two ternary mixtures of ibuprofen (I), lactose $(\mathrm{L})$ or tricalcium phosphate $(\mathrm{P})$ and microcel $(\mathrm{M})$ in the relative proportions 2:3:5 (ILM or IPM) and two four-component mixtures of the same components plus $5 \%$ citric acid (C) in the relative proportions 2:2.5:0.5:5 (CILM or CIPM). Demineralysed water, $65 \%$ in volume to weight of dry matter $(\mathrm{v} / \mathrm{w})$, was used as the wetting liquid. The powders were mixed for $5 \mathrm{~min}$ (Kenwood mixer, UK) before the water was added. Masses were extruded in an extruder with cylinders (Caleua Model 10, Dorset, England), fitted with a die of $1 \mathrm{~mm}$ diameter (Caleva Process, Ltd., Dorset, UK). The extrudate was spheronized in a spheronizer (G.B. Caleva, Ltd., Dorset, UK) fitted with a radial cut plate, $250 \mathrm{~mm}$ diameter at $1020 \mathrm{rpm}$ for $4 \mathrm{~min}$. The pellets obtained were dried in a fluidized bed dryer (Glatt, Binzen, Germany), for $10 \mathrm{~min}$ at $50^{\circ} \mathrm{C}$. Pellets were then submitted to sieve analysis using a set of British Standard sieves following a $\sqrt{2}$ progression from 500 to $2000 \mu \mathrm{m}$ of mesh diameter, and a mechanical sieve shaker, during $10 \mathrm{~min}$. Pellets characterization, for each formulation, was performed on the size range of 1000-1400 $\mu \mathrm{m}$. 


\subsection{Pellets characterization}

\subsubsection{Crushing strength}

Strength testing was performed in 20 pellets of each formulation with an available Erweka radial force apparatus (Erweka GmbH, Heusenstamm, Germany).

\subsubsection{Specific surface area}

The specific surface area of pellets for all formulations was determined using the adsorption isotherm derived by the Brunauer, Emmet and Teller (BET) method as described by Sousa et al. (2002a). The analysis was performed by a certified laboratory (LabGran-Instituto Pedro Nunes, Coimbra, Portugal), using qualified equipment (ASAP 2000, Micromeritics). In general, one determination was deemed sufficient but with one sample (ILM) three were carried out for validation purposes.

\subsubsection{Density and porosity}

Bulk and apparent densities, porosity, togheter with porosity parameters, such as the mean pore diameter, total pore volume, pore size distributions and pores shapes, were determined before, during $(t=15 \mathrm{~min})$, and after dissolution $(t=480 \mathrm{~min})$ using a qualified mercury porosimeter (Poresizer 9320, Micromeritics). The analysis was also performed by the above mentioned laboratory and again three determinations were made for the ILM sample. The method is based on the intrusion of mercury under pressure into the sample pores and is quantified using the adapted Washburn equation (Lowell and Shields, 1991; Mehta et al., 2000),

$D=\frac{-4 \gamma \cos \theta}{P}$

where $D$ is the pore diameter, $\gamma$ is the surface tension of mercury $(485 \mathrm{dyn} / \mathrm{cm}), \theta$ is the contact angle $\left(130^{\circ}\right)$ and $P$ is the pressure $(\approx 2-30,000$ psia). From the above equation, a relationship between pore diameter and pore volume of a porous material can be obtained by measuring the apparent volumes. The total pore surface area $(S)$ is given by

$S=\frac{\int_{0}^{V_{\text {tot }}} P \mathrm{~d} V}{\gamma|\cos \theta|}$

where $P$ is the pressure, $V$ is the intruded volume of mercury and $V_{\text {tot }}$ is the total intruded volume of mer- cury. The mean pore diameter $\left(D_{\text {mean }}^{\prime}\right)$ is calculated from

$D_{\text {mean }}^{\prime}=\frac{4 V_{\text {tot }}}{S}$

Pore shape is, in turn, inferred from the mercury intrusion-extrusion hysteresis.

\subsubsection{Scanning electron microscopy}

SEM was performed using a JEOL JSM-5310 scanning electron microscope (JEOL, Tokyo, Japan).

\subsubsection{In vitro dissolution studies}

Dissolution was conducted in a USP (Method 1, rotating basket) apparatus, at a speed of $100 \mathrm{rpm}$, in $6 \times 900 \mathrm{ml}$ of dissolution media (phosphate buffer at $\mathrm{pH} 7.2 \pm 0.05)$, maintained at $37 \pm 0.5^{\circ} \mathrm{C}$, using an automated assembly which consisted of a Fujitsu Ergo Proe PC, with UV-1601PC software, a peristaltic pump (Watson Marlow 205S, UK), a UV spectrophotometer (Shimadzu UV-1603, Kyoto, Japan), cell positioner (Shimadzu CPS-Controller, Kyoto, Japan), and water bath fitted with a variable-speed stirrer (Vankel UK7000, Essex, UK) and a heater (Vankel VK750D, Essex, England). The released ibuprofen absorbance was recorded automatically at $264 \mathrm{~nm}$ every $5 \mathrm{~min}$ for $8 \mathrm{~h}$. The test was carried out in triplicate and a total of 18 dissolution curves were obtained for each formulation. Mean dissolution times (MDT) at different time points were determined from mean profiles obtained from these 18 curves, as described previously (Costa et al., 2003). In the original reference, variances of dissolution times are also included. Tests conducted with pellets in which the active substance is absent have shown no absorption in the wavelength considered. After $480 \mathrm{~min}$ of dissolution, pellets were dried under vacuum at $50^{\circ} \mathrm{C}$ and weighed to determine the percentage of weight loss.

\section{Results and discussion}

\subsection{Specific surface area, densities and porosity}

The specific area, apparent density and solubility of excipients are shown in Table 1. Tricalcium phosphate, used as an insoluble filler, presents a significantly higher value for the specific surface area than the other 
Table 2

Pellet physical properties

\begin{tabular}{|c|c|c|c|c|}
\hline Properties & ILM & CILM & IPM & CIPM \\
\hline Crushing strength $(\mathrm{N})$ & $6.66 \pm 1.08$ & $9.80 \pm 1.57$ & $3.53 \pm 0.78$ & $5.10 \pm 1.08$ \\
\hline Specific surface area $\left(\mathrm{m}^{2} \mathrm{~g}^{-1}\right)$ & $0.47 \pm 0.01$ & 0.33 & 15.77 & 10.76 \\
\hline Bulk density $\left(\mathrm{g} \mathrm{cm}^{-3}\right)$ & $1.19 \pm 0.01$ & 1.32 & 1.19 & 1.26 \\
\hline Apparent density $\left(\mathrm{g} \mathrm{cm}^{-3}\right)$ & $1.44 \pm 0.01$ & 1.51 & 1.70 & 1.61 \\
\hline Porosity (\%) & $17.78 \pm 0.55$ & 13.10 & 29.78 & 24.28 \\
\hline Total pore surface area $\left(\mathrm{m}^{2} \mathrm{~g}^{-1}\right)$ & $7.91 \pm 0.37$ & 7.72 & 25.97 & 20.45 \\
\hline Median pore diameter $(\mu \mathrm{m})$ & $1.11 \pm 0.02$ & 0.54 & 0.10 & 0.10 \\
\hline
\end{tabular}

Uncertainties are indicated for replicated determinations.

materials and is also characterized by the highest apparent density of all powders used. These properties are reflected, as expected (Sousa et al., 1996, 2002b), in the physical characteristics of the pellets obtained (Table 2). In fact, specific surface area and apparent density of the IPM and CIPM pellets are higher than of those with lactose, indicating that they offer a larger contact surface with the surroundings. This explains their higher porosity values, with a 5 to 10 times smaller median pore diameter and a smaller pellet crushing strength than those containing lactose. This larger contact surface is also shown by the lower bulk density values in the IPM and CIPM pellets.

The porosity and specific surface area characteristics indicate that drug release and dissolution from the phosphate pellets is generally faster than with other insoluble excipients (Mehta et al., 2000; Sousa et al., 2002a). This is observed in the first $15 \mathrm{~min}$ of dissolution where MDT values are very similar for the ILM and IPM pellets (see Table 3). For the same time period, both the CILM and CIPM formulations resulted in higher MDT values, indicating a delay in dissolution. This is shown in Fig. 1, which represents the drug percent dissolved for formulations IPM, CIPM and

Table 3

Pellet physical properties after dissolving for $15 \mathrm{~min}$

\begin{tabular}{lrrrr}
\hline Properties & ILM & CILM & IPM & CIPM \\
\hline Bulk density $\left(\mathrm{g} \mathrm{cm}^{-3}\right)$ & 0.87 & 1.03 & 1.12 & 1.07 \\
Apparent density $\left(\mathrm{g} \mathrm{cm}^{-3}\right)$ & 1.38 & 1.40 & 1.70 & 1.64 \\
Porosity (\%) & 36.87 & 26.87 & 34.23 & 34.48 \\
Total pore surface & 11.45 & 12.4 & 27.97 & 24.18 \\
$\quad$ area $\left(\mathrm{m}^{2} \mathrm{~g}^{-1}\right)$ & & & & \\
Median pore diameter $(\mu \mathrm{m})$ & 1.93 & 1.18 & 0.18 & 0.60 \\
MDT (min) & 5.96 & 7.58 & 5.92 & 6.86 \\
\hline
\end{tabular}

The corresponding MDT values are also given.
CILM versus drug percent dissolved for ILM Fig. 1(a) and the correspondent time derivatives plot Fig. 1(b). These representations emphasize the effects on the beginning of dissolution, which would not otherwise be easily observed resorting to more common dissolution representations (e.g., Fig. 2) (Costa et al., 2003). In spite of a slower initial release, the formulation CIPM, due to an intermediate increase in rate, is the first to attain complete dissolution. Formulation CILM is, in turn, characterized by a slower release and is the one that takes longer to attain complete dissolution. The similarity is also clear between formulations ILM and IPM. Fig. 1(a) also clearly shows the initial zero order release in the case of formulation CILM.

\subsection{The effects of citric acid}

Dissolution results are in agreement with what is expected from previous work (Goskonda et al., 1994; Healy and Corrigan, 1996; Nykänen et al., 1999; Krogars et al., 2000), using 5\% citric acid in CILM and CIPM formulations. During dissolution testing, there is the possibility of an acidic micro-environment existing inside and in the closer vicinity of the pellets, in spite of the presence of the buffer in the bulk solution, making ibuprofen dissolution difficult and promoting a delay in its release, since ibuprofen is an acidic drug ( $\mathrm{p} K_{\mathrm{a}}$ 4.4) (AHFH, 2002). The modeling of the role of citric acid can also be shown through its influence on porosity parameters. In fact, specific surface area values for formulations containing citric acid are lower than those for the correspondent formulations in the absence of this excipient. Bulk density values are higher, lessening the penetration of the dissolution medium in the pellet, and also favoring the above mentioned acidic micro-environment. This, in turn, 

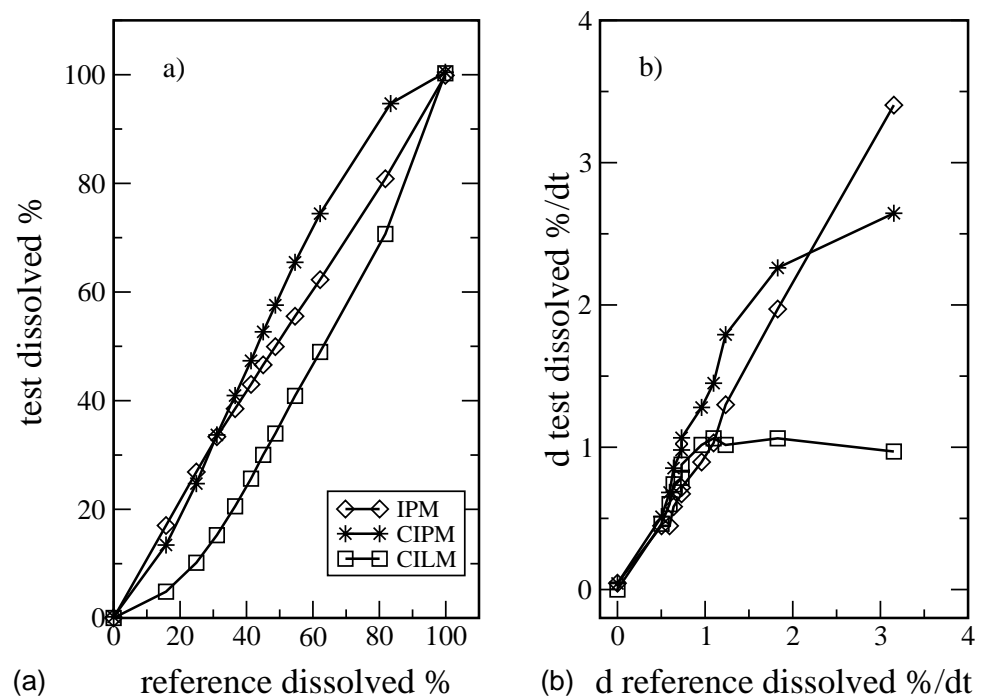

Fig. 1. Graphical representations of: (a) test formulations IPM, CIPM and CILM dissolved drug percentage as a function of that of formulation ILM (reference); (b) test formulations dissolved drug percentage time derivative as a function of the corresponding values for the reference $(n=18)$.

diminishes the rates of both drug release and dissolution. In addition, we can observe that the presence of citric acid decreases the median pore diameter in lactose pellets, contributing to the delay in drug release. The values of these porosity parameters are related to the high solubility of citric acid and its influence during pellets processing and drying. When water is being removed during the drying phase, the dissolved substances recrystallyse (Berggren and Alderborn, 2001; Sousa et al., 2002b) and inter-particle distance decreases, thus lowering porosity and pore size. In CIPM pellets, citric acid does not produce such a pronounced effect as in CILM pellets, due mainly to the insolubility of the filler. In this case, during dissolution, large areas of ibuprofen particles are surrounded by tricalcium phosphate, and are thus not directly

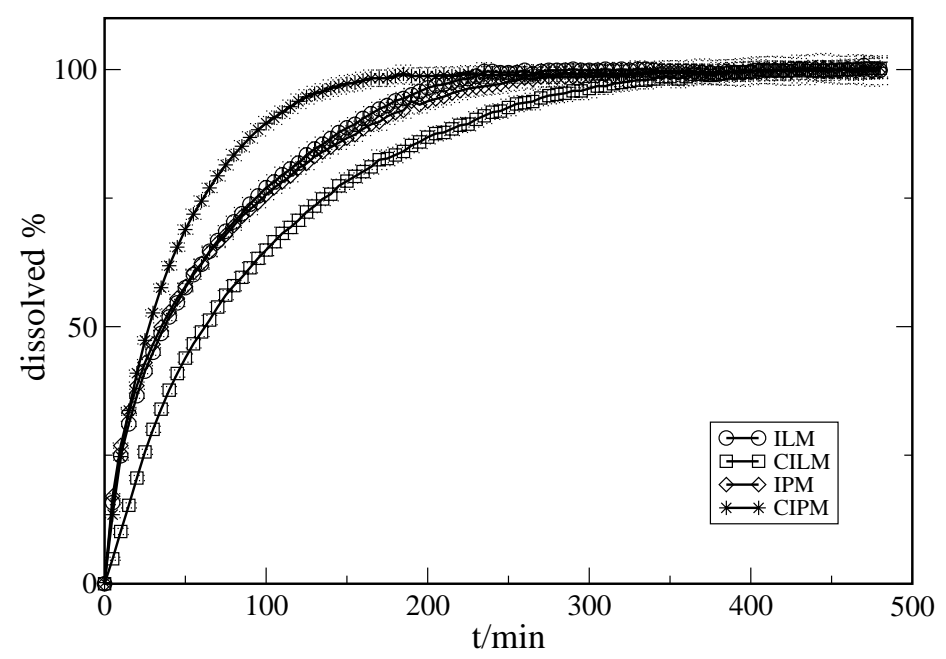

Fig. 2. Dissolution profiles of formulations ILM, CILM, IPM and CIPM $(n=18)$. 
adjacent to the dissolving acid excipient. This diminishes the delaying influence of citric acid on solubility and dissolution (Healy and Corrigan, 1996). Moreover, as we have seen above for the CILM formulation, this delay is maintained until the end of dissolution, while for CIPM a release compensation occurs.

In summary, ILM and IPM present similar MDT values. Lactose is a soluble excipient, but displays a lower specific surface area than the insoluble tricalcium phosphate. For the latter, the large difference between bulk and apparent densities associated with a small median pore diameter suggests the existence of air entrapment, causing a delay on the dissolution medium penetration and, in consequence, in the drug release. Addition of citric acid causes a delay in the initial part of dissolution in both lactose and phosphate formulations, but the overall release is faster for phosphate than lactose pellets. This difference may be explained by the fact that in CIPM pellets, citric acid dissolution "opens the way" to drug release, increasing the contact surface with the solvent and facilitating its ingress.

\subsection{Variation of porosity parameters during dissolution}

All our formulations contain microcrystalline cellulose and, as other authors have previously reported (Santos et al., 2002; Tho et al., 2002), pellets do not disintegrate during in vitro dissolution. They were recovered at dissolution times $t=15 \mathrm{~min}$ and $t=$ $480 \mathrm{~min}$, dried and submitted to mercury porosimeter analysis (see Tables 3 and 4). Point $t=15$ min was chosen because it corresponds to the change point in dissolution rate of CIPM pellets (see Fig. 1), and point $t=480 \mathrm{~min}$ is the last point in all dissolution curves. As expected, porosity and median pore diameter are found to increase with dissolution in all cases (see Fig. 3). Samples collected at the first 15 min of dissolution show that initially there is a drastic increase in these properties, especially for IPM and CIPM formulations, indicating that diffusion through the pores is probably the main mechanism ruling the drug release (Vergote et al., 2001). However, a certain degree of erosion in the inside of pores must also concomitantly take place. The initial ratio between median pore diameters in pellets containing lactose and pellets with tricalcium phosphate is, grosso modo, maintained during dissolution. The same does not apply for porosity values, once formulations containing lactose attain full dissolution of the active substance with a much higher increase in porosity than formulations containing tricalcium phosphate. This is mainly due to the substantial weight loss of ca. 50\% in ILM and CILM pellets, due to dissolution of excipients with the exception of microcel (Table 4).

As discussed before, during dissolution pellets containing citric acid perform very differently depending on whether the filler is lactose or tricalcium phosphate. Citric acid reduces lactose pellets median pore diameter in comparison to those corresponding to ILM and for the extracted samples collected along dissolution. In contrast, this parameter is increased considerably along dissolution, now comparing to the IPM formulation. These findings may justify the different behaviors at later stages of dissolution of formulations CILM and CIPM.

The drug release rates are dependent, thus, not only on porosity values but also on total pore surface area and median pore diameter. The CIPM formulation,

Table 4

Pellet physical properties after complete dissolution (480 min)

\begin{tabular}{lcccc}
\hline Properties & ILM & CILM & IPM & CIPM \\
\hline Bulk density $\left(\mathrm{g} \mathrm{cm}^{-3}\right)$ & 0.76 & 0.83 & 1.07 & 1.06 \\
Apparent density $\left(\mathrm{g} \mathrm{cm}^{-3}\right)$ & 1.31 & 1.32 & 1.77 & 1.74 \\
Porosity $(\%)$ & 42.04 & 37 & 39.59 & 39.27 \\
Total pore surface area $\left(\mathrm{m}^{2} \mathrm{~g}^{-1}\right)$ & 13.28 & 15.23 & 33.62 & 29.47 \\
Median pore diameter $(\mu \mathrm{m})$ & 2.62 & 1.76 & 6.21 & 1.43 \\
MDT (min) & 60 & 93 & $20.66 \pm 0.49$ & 46 \\
Weight loss after dissolution & $50.52 \pm 0.54$ & $50.21 \pm 0.4$ & & $25.67 \pm 0.29$ \\
$\quad$ testing $(\%)$ & & & & \\
\hline
\end{tabular}

The corresponding MDT values and final weight losses are also presented. 


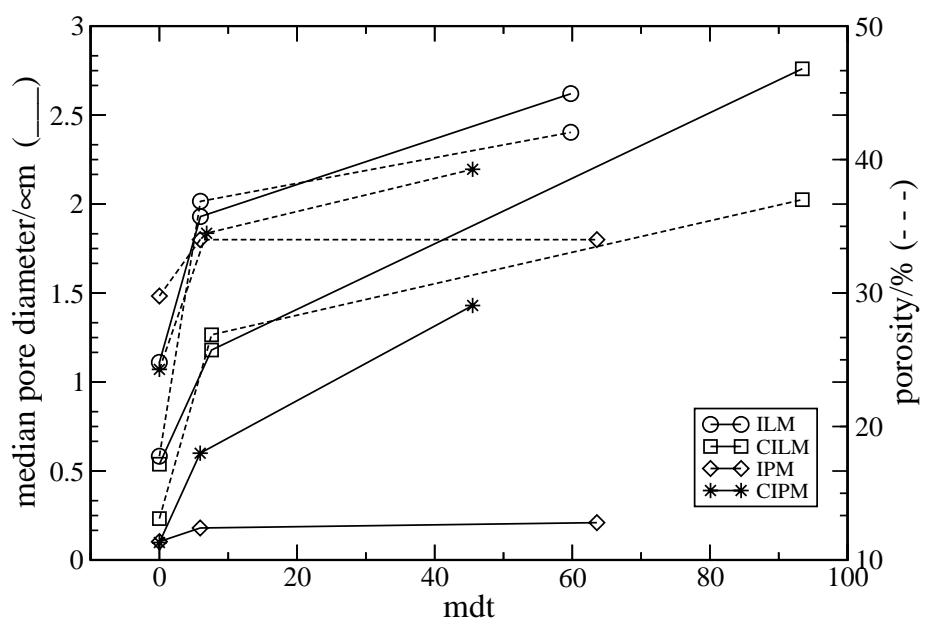

Fig. 3. Relationship between MDT values for the various formulation and median pore diameters (solid line) and porosities (dotted line). Lines were used for guiding the eye only.

which displays the fastest overall release, presents during dissolution a high porosity, a high total pore surface area values, and a median pore diameter of ca. $1 \mu \mathrm{m}$. The IPM formulation, on the other hand, has a median pore diameter of ca. $0.2 \mu \mathrm{m}$. It also seems that

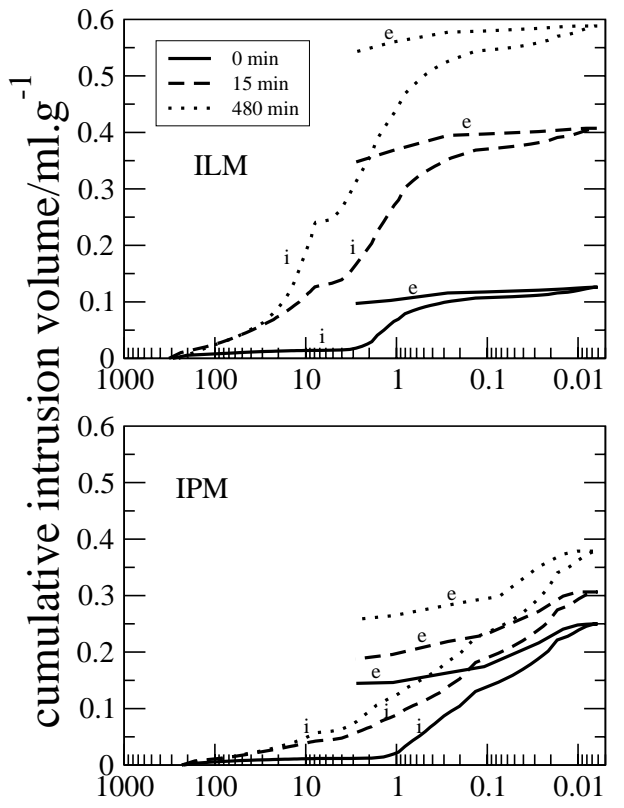

high porosity and total pore surface area with small median pore diameter (less than $1 \mu \mathrm{m}$ ) produces similar dissolution results to those of low porosity and low total pore surface area values in conjunction with a high median pore diameter.
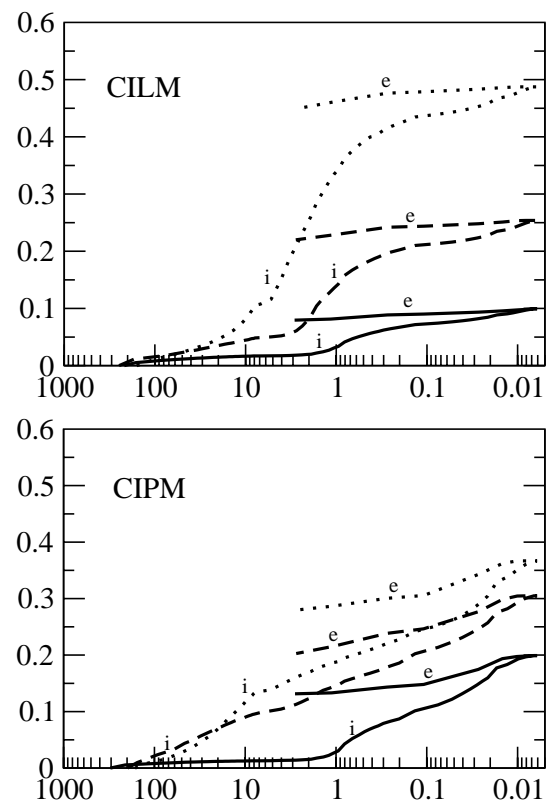

mean pore diameter/ $\mu \mathrm{m}$

Fig. 4. Mercury intrusion (i) and extrusion (e) curves for formulations ILM, CILM, IPM and CIPM, at the indicated time points. 


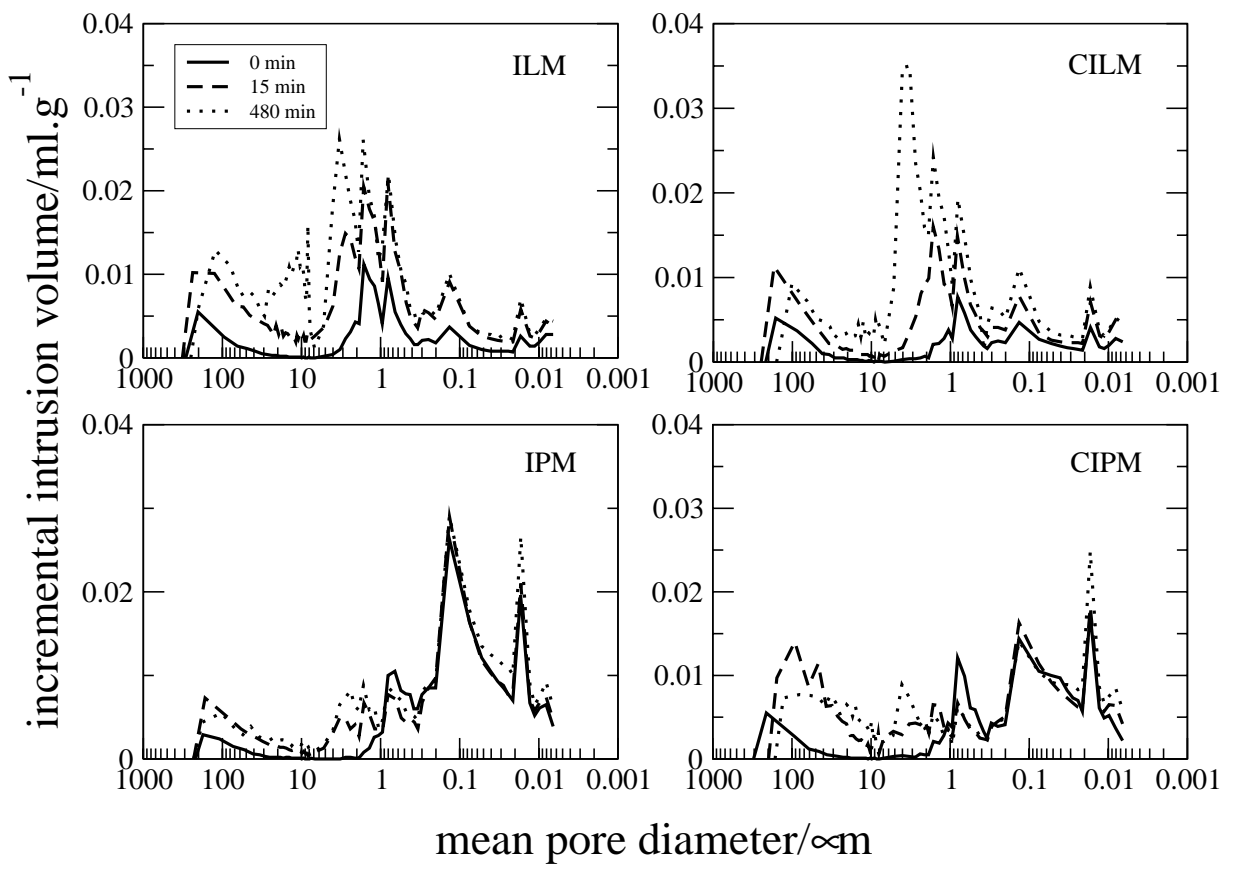

Fig. 5. Pellet pore size distribution at the different time points.

\subsubsection{Shape and pore size distribution}

Fig. 4 shows the cumulative intrusion-extrusion mercury volume plotted versus the mean pore diameter of the four formulations considered before $(t=0 \mathrm{~min})$, during $(15 \mathrm{~min})$ and after dissolution (480 min). Fig. 5 shows the incremental intrusion volume and also the mean pore diameter of the same formulations. From these figures we can see that all formulations have pores with a large range of sizes and with significant differences in the respective frequency. Pellets containing lactose suffer drastic changes during dissolution while those with tricalcium phosphate only show modest variations (Fig. 5). However, the CIPM structure presents a considerable increment of frequency related to the higher values of pore diameters $(10-100 \mu \mathrm{m})$, which explains the relative high values of its median pore diameters during and after dissolution.

All cumulative intrusion curves (Fig. 4) show hysteresis connected to mercury pore entrapment (Fujiwara et al., 1966; Orr, 1970; Lowell and Shields, 1991). This could be due to larger pore base diameters in relation to pore entrance diameters. This corresponds to a significant fraction of pores with an "ink-bottle" shape as previously reported (Shively, 1991; Mehta et al., 2000; Byrne and Deasy, 2002). In pellets containing lactose, the extruded mercury volume is smaller than that in the tricalcium phosphate pellets, indicating that the pore base dimensions of ILM and CILM pellets are higher, relatively to the entrance parameter diameter, than those from the CIPM and IPM pellets. Other supporting evidence for this is the huge difference between specific surface area determined by gas adsorption and total pore area determined by mercury penetration, specially for ILM and CILM pellets (see Table 2). With this last method, intrusion into the wide pore inner body will not occur until sufficient pressure is applied to force the mercury into the narrow entrance. It will, therefore, appear as if a large volume was intruded into narrow pores, generating an excessively high calculated surface area (Lowell and Shields, 1991).

The CILM pellets at $t=15 \mathrm{~min}$ and $t=480 \mathrm{~min}$ have a high frequency of mean pore diameters in the $0.3-3 \mu \mathrm{m}$ range (Fig. 5). However, this could imply some pores with this entrance diameter range and a wide inner body, rather than a large number of pores 

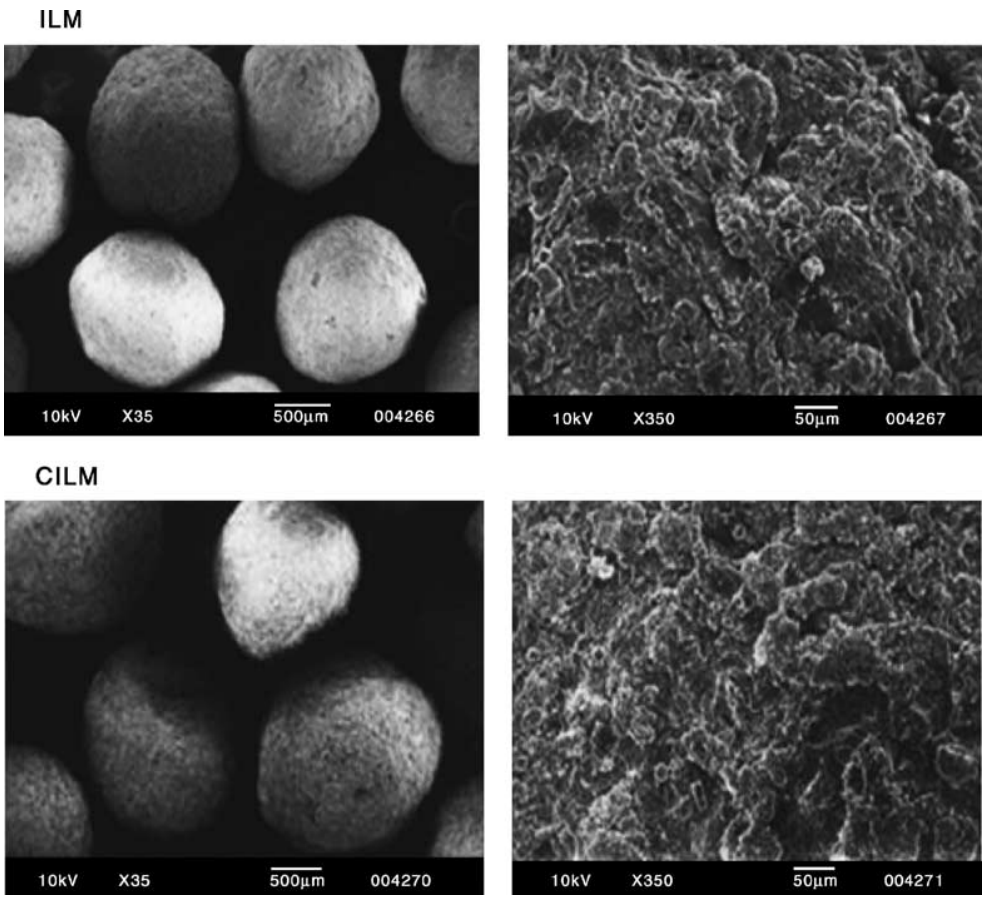

Fig. 6. SEM micro-photographs of ILM and CILM formulations. Magnifications: $35 \times$ and $350 \times$.
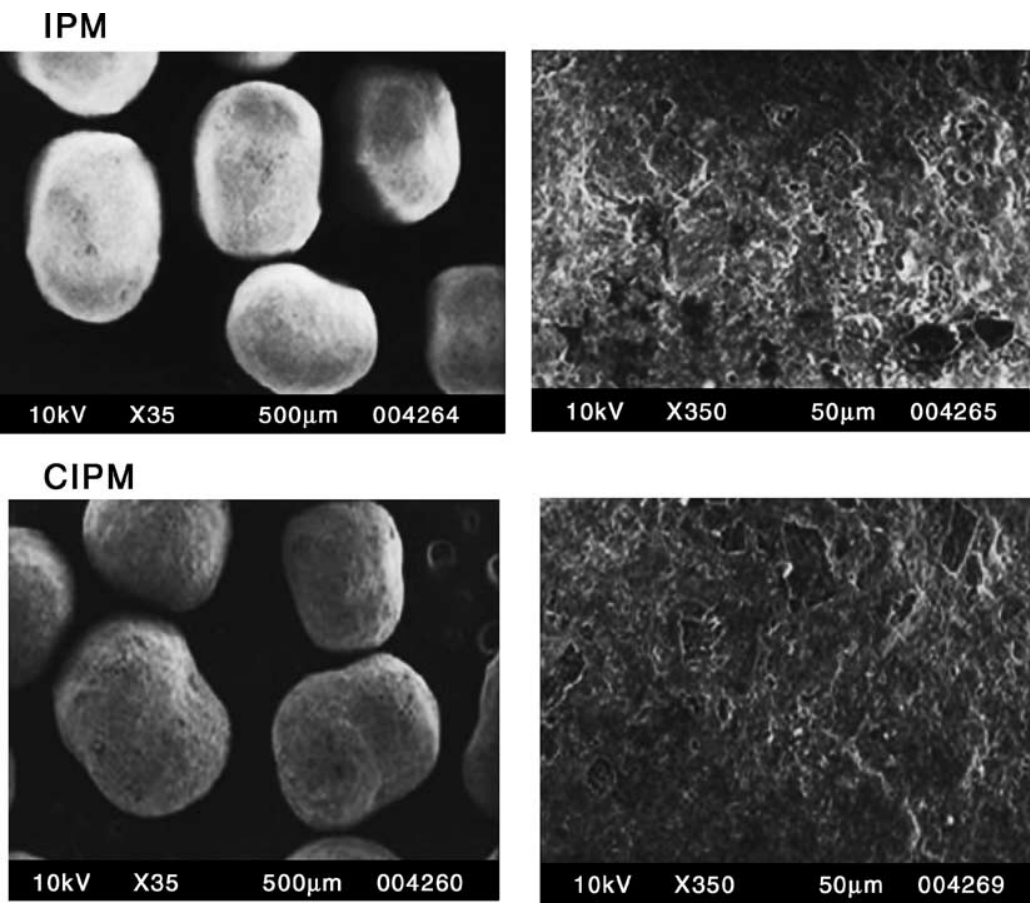

Fig. 7. SEM micro-photographs of IPM and CIPM formulations. Magnifications: $35 \times$ and $350 \times$. 
with these dimensions. This could emerge as an additional factor for the drug release delay observed with this formulation.

\subsection{SEM}

Micro-photographs of the four considered pellets formulations are shown in Figs. 6 and 7. One can see that IPM and CIPM pellets have a smoother surface than ILM and CILM pellets, due to their tiny pore entrance diameters, which could be a valuable property for subsequent technological treatment (e.g. coating and packing).

\section{Conclusions}

Pellets with the soluble filler lactose and pellets containing the insoluble filler tricalcium phosphate have produced similar in vitro release profiles of the model drug ibuprofen. On the other hand, when $5 \%$ of fillers were replaced by citric acid, we have witnessed different dissolution behaviors, i.e., in lactose pellets citric acid induced a drug release delay, while in tricalcium phosphate pellets a delay was noticed only during the first $15 \mathrm{~min}$, with this formulation being the first to reach complete dissolution.

Porosity and porosity parameters, such as total pore surface area, mean pore diameter, pores size distribution and pores shape, contribute to explain this findings and, along with excipients physical properties as solubility, density and specific surface area, can help predicting drug release profiles of multi-unit dosage forms.

Tricalcium phosphate containing pellets prove to be smoother, due to their high porosity values and low pore sizes, which is a useful property to consider for subsequent technological treatment.

\section{Acknowledgements}

The authors thank Prof. H.D. Burrows (University of Coimbra) for a critical reading of the manuscript.

\section{References}

AHFH Drug Information, 2002. American Society of HealthSystem Pharmacists, Maryland.
Alvarez, L., Concheiro, A., Gómez-Amoza, J.L., Souto, C., Martínez-Pacheco, R., 2002. Effect of microcrystlline cellulose grade and process variables on pellets prepared by extrusionspheronization. Drug Dev. Ind. Pharm. 28, 451-456.

Berggren, J., Alderborn, G., 2001. Effect of drying rate on porosity and tabletting behaviour of cellulose pellets. Int. J. Pharm. 227, 81-96.

Byrne, R.S., Deasy, P.B., 2002. Use of commercial porous ceramic for sustained drug delivery. Int. J. Pharm. 246, 61-73.

Chopra, R., Newton, J.M., Alderborn, G., Podczeck, F., 2001. Preparation of pellets of different shape and their characterization. Pharm. Dev. Tech. 6, 495-503.

Conine, J.W., Hadley, H.R., 1970. Preparation of small solid spheres. Drug Cosmet. Ind. 106, 38-41.

Costa, F.O., Sousa, J.J.S., Pais, A.A.C.C., Formosinho, J.S., 2003. Comparison of dissolution profiles of ibuprofen pellets. J. Control Rel. 89, 199-212.

Dees, P.J., Polderman, J., 1981. Mercury porosimetry in pharmaceutical technology. Powder Tech. 29, 187-197.

Fujiwara, H., Toda, J., Kato, M., 1966. Studies on pore structure of granules by mercury porosimetry. Chem. Pharm. Bull. 14, 601-607.

Goskonda, S.R., Hileman, G.A., Upadrashta, S.M., 1994. Controlled release pellets by extrusion-spheronization. Int. J. Pharm. 111, 89-97.

Healy, A.M., Corrigan, O.I., 1996. The influence of excipient particle size, solubility and acid strength on the dissolution of an acidic drug from two-component compacts. Int. J. Pharm. 143, 211-221.

Handbook of Pharmaceutical Excipients, 2000. American Pharmaceutical Association, Washington DC and Pharmaceutical Press, London.

Johansson, B., Alderborn, G., 2001. The effect of shape and porosity on the compreession behaviour and tablet forming ability of granular materials formed from microcrystalline cellulose. Eur. J. Pharm. Biopharm. 52, 347-357.

Khan, G.M., Zhu, J.B., 1998. Ibuprofen release kinetics from controlled-release tablets granulated with aqueus polymeric dispersion of ethylcellulose. II: Influence of several parameters and coexcipients. J. Control Rel. 56, 127-134.

Krogars, K., Heinämäki, J., Vesalahti, J., Marvola, M., Antikainen, O., Yliruusi, J., 2000. Extrusion-spheronization of pH-sensitive polymeric matrix pellets for possible colonic drug delivery. Int. J. Pharm. 199, 187-194.

Lowell, S., Shields, J.E., 1991. Powder Surface Area and Porosity, 3rd ed. Chapman \& Hall, New York.

Mehta, K.A., Kislalioglu, M.S., Phuapradit, W., Malick, A.W., Shah, N.H., 2000. Effect of formulation on process variables and porosity parameters and release rates from a multi unit erosion matrix of a poorly soluble drug. J. Control Rel. 63, 201-211.

Nykänen, P., Krogars, K., Säkkinen, M., Heinämäki, J., Jürjensson, H., Veski, P., Marvola, M., 1999. Organic acids as excipients in matrix granules for colon-specific drug delivery. Int. J. Pharm. 184, 251-261.

Orr Jr., C., 1970. Application of mercury penetration to materials analysis. Powder Tech. 3, 117-123. 
Pinto, J.F., Lameiro, M.H., Martins, P., 2001. Investigation on the co-extrudability and spheronization properties of wet masses. Int. J. Pharm. 227, 71-80.

Reynolds, A.D., 1970. PA new technique for the production of spherical particles. Manufact. Chem. Aerosol. News 41, 4043.

Rodriguez, E.C., Torrado, J.J., Nikolakakis, I., Torrado, S., Lastres, J.L., Malamataris, S., 2001. Micromeritic and packing properties of diclofenac pellets and effects of some formulation variables. Drug Dev. Ind. Pharm. 27, 847-855.

Santos, H., Veiga, F., Pina, M., Podczeck, F., Sousa, J., 2002. Physical properties of chitosan pellets produced by extrusion-spheronization: influence of formulation variables. Int. J. Pharm. 246, 153-169.

Shively, M.L., 1991. Analysis of mercury porosimetry for the evaluation of pore shape and intrusion-extrusion hysteresis. J. Pharm. Sci. 80, 376-379.

Sousa, J., Sousa, A., Moura, M., Podczeck, F., Newton, J., 2002a. The influence of core materials and film coating on the drug release from coated pellets. Int. J. Pharm. 233, 111122.

Sousa, J., Sousa, A., Podczeck, F., Newton, J., 2002b. Factors influencing the physical characteristics of pellets obtained by extrusion-spheronization. Int. J. Pharm. 232, 91-106.

Sousa, J.J., Sousa, A., Podczeck, F., Newton, J.M., 1996. Influence of process conditions on drug release from pellets. Int. J. Pharm. 144, 159-169.

Tho, I., Sande, S.A., Kleinebudde, P., 2002. Pectinic acid, a novel excipient for production of pellets by extrusion/spheronization: preliminary studies. Eur. J. Pharm. Biopharm. 54, 95-99.

Tomer, G., Podczeck, F., Newton, J.M., 2001. The influence of type and quantity of model drug on the extrusion/spheronization of mixtures with microcrystalline cellulose. I. Extrusion parameters. Int. J. Pharm. 217, 237-248.

Vergote, G.J., Vervaet, C., Driessche, I.V., Hoste, S., Smedt, S.D., Demeester, J., Jain, R.A., Ruddy, S., Remon, J.P., 2001. An oral controlled release matrix pellet formulation containing nanocrystalline ketoprofen. Int. J. Pharm. 219, 81-87. 